\title{
SOIL ERODIBILITY AND SOIL SUSCEPTIBILITY TO EROSION BY WATER IN SHONKOLA MOUNTAINOUS AREA OF SORO DISTRICT, ETHIOPIA
}

\author{
Kibemo Detamo Aga* \\ Department of Geography and Environmental Studies, Wachemo University, Hosanna, Addis Ababa, \\ Ethiopia
}

*Corresponding Author Email id: kibemodetamo86@gmail.com

Received: 3.11.2020; Revised: 21.11.2020; Accepted: 25.11.2020

CSociety for Himalayan Action Research and Development

\begin{abstract}
Although the problem of soil erosion is common in all countries, it is one of the more persisting hazards in developing countries like Ethiopia which is a country located in tropic where there is higher precipitation and is vulnerable to almost all forms of environmental degradation which is also resulted from poor resource conservation practices. The main objective of this study is to determine soil erodibility and susceptibility to soil erosion in Shonkola mountainous area, Soro district. To determine soil erodibility and susceptibility to soil erosion, the percentage of primary soil separates (silt, very fine sand, and clay); percentage of organic matter; soil structure classes; and soil permeability were estimated. Soil samples were collected from 56 locations at an average depth of $15 \mathrm{~cm}$ to employ soil texture nomograph. Thus, soil erodibility of Shonkola area is determined and mapped to envisage the area that is highly susceptible for soil erosion. The soil erodibility value ranges from 0.01426 to 0.04001. It was found that the soil erodibility increases as organic content decreases, soil texture becomes finer and less permeable, and structure becomes poor. Prediction of soil erodibility and susceptibility to soil erosion is of great importance for soil erosion quantification, using GIS. The farm-unit level identification of soil types and existing specific problems are crucial in planning and implementation of any soil management strategies.
\end{abstract}

Keywords: Soil erodibility, Soil susceptibility, Soro district

\section{Introduction}

Soil erosion by water is a world major problem that results in decrease of soil fertility, land degradation, and also affects the sustainability and productivity of agricultural areas (Hussein et al., 2016; Tsitsagi et al. 2018). Moreover, since the soil erosion is a wide spread problem in agriculture in the developing countries, it has a far-reaching economic, political, social and environmental implications due to both on-site and off-site damages. About more than 4900 million ha $(33 \%)$ of the soils around the planet have been affected by processes of degradation (Lal, 2015). The importance of land degradation among global issues is heightened because of its impact on world food security and quality of the environment (Menale and Holden, 2006; Vlek et al., 2010; Shimeles, 2012). Consequently, globally, about 1.5 billion people (21.5 per cent) and 42 per cent of the poor live on degraded lands (IFPRI, 2012). Each year, 75 billion tons of the soil is vanished due to water erosion, with most of it coming from farmland and a result, about 20 million hectares of land in lost. Soil erosion is very high in Asia, Africa and South America averaging 30-40 t/ha/year (Barrow, 1991).

Although the causes and the consequences of soil degradation have long been identified, the attempts made to mitigate the soil loss were not comprehensive in terms of their spatio-temporal extents, approaches and applications. Despite the 
availability of spatio-temporal data, researchers in most developing countries are unable to abundantly access such data due to financial shortcomings and lack of smooth-information flow. Usually explained soil erosion estimation parameters using Revised Universal Soil Loss Equation (RUSLE) are rainfall erosivity, soil erodibility, slope length and slope steepness, vegetation cover and human support factors.

Soil erodibility represents soil susceptibility to suffer detachment by water erosion processes and determined separately (Goldman et al., 1986; Renard et al., 1997; Thakur, 2012; Manyiwa and Dikinya, 2013; Panagos et al., 2014; Suraj et al., 2019).

\section{Materials and Methods}

Study Area: Shonkola area located in Soro District, which is a mountainous terrain in Hadiya Zone that is one of the zones in Southern Nations, Nationalities and Peoples Regional State (SNNPR) of Ethiopia. The Shonkola area is highly undulating and exhibits the typical highland terrain of Southwestern highlands as area is western escarpment of Ethiopian main Rift Valley with a range of elevation from $1815 \mathrm{~m}$ to $2845 \mathrm{~m}$ above sea level. The study area covers $185.4 \mathrm{~km}^{2}$ and lies between latitudes $7^{\circ} 21^{\prime} 00^{\prime \prime} \mathrm{N}$ to $7^{\circ} 17^{\prime}$ $34^{\prime \prime} \mathrm{N}$ and longitudes $37^{\circ} 33^{\prime} 37^{\prime \prime} \mathrm{E}$ to $37^{\circ} 48^{\prime} 15^{\prime \prime} \mathrm{E}$ (Figure 1) and located at $25 \mathrm{~km}$ South of Hosanna town, administrative town of Hadiya Zone. Study area is characterized by bimodal precipitation that receives heavy rainfall during summer season (Kiremt), yet the rain of spring season (Belg) has considerable importance. Winter time is almost dry and less rainy, as result it is the harvest season. The annual average precipitation at study ranges from $74 \mathrm{~mm}$ minimum to $152.5 \mathrm{~mm}$ maximum with a mean minimum and maximum temperature of $18.5^{\circ} \mathrm{C}$ and $20.7^{\circ} \mathrm{C}$, respectively. However, the summer season (June, July and August) precipitation average reaches up to 1319 $\mathrm{mm}$. As result of recurrent land degradation, soil erosion and higher elevation, the area has a rouged topography, in which many rivers originate and discharge towards southwest that finally empty to Gibe-Omo River, one of the drainage system of Ethiopia.

The study area is dominated by rain-fed agriculture of cereals, pulse and some oilseeds. Although different land uses have been observed, forest is confined to pocket area.

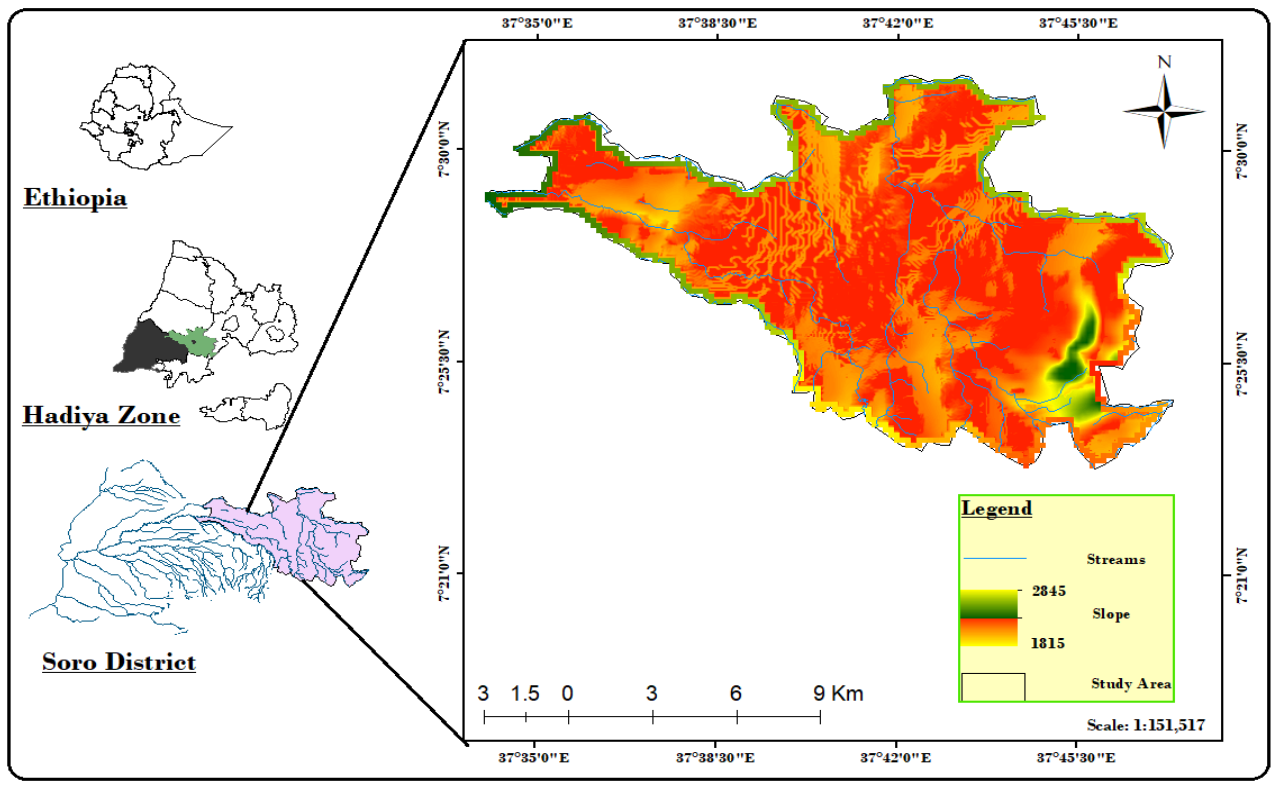

Figure 1: Location map of study area 


\section{Methods}

Soil Erodibility: Ethiopia has about 18 "Major soil groups" with varying area coverage and physico-chemical properties (FAO/UNESCO, 1981; Berhanu, 1985). Using the databases of United Nations Food and Agricultural Organization (FAO) and the soil association of Ethiopia, the soil unit map of Shonkola mountainous area, was subset through the use of "Spatial Analyst Tool" Extract by Mask".To estimate soil erodibility, soil texture nomograph that is the chart that measures the proportion of particle sizes as percentage of clay, silt and sand in broad.

For the soils containing less than 70 per cent silt and very fine sand, the preferable method, according to Renard et al. (1997) and Goldman et al (1986), for determining soil erodibility is the nomograph method based on the work by Wischmeier and Smith (1978) and is mathematically represented as follows:

$100 \mathrm{~K}=2.1 \times 10^{-4}(12-0 \mathrm{M}) \mathrm{M}^{1.14}+3.25(\mathrm{SS}-2)+2.5(\mathrm{PP}-3) \ldots \ldots[1]$

Where, $\mathrm{K}$ is soil erodibility factor (metric ton $/ \mathrm{ha} / \mathrm{mm}^{-1} /$ year); $\mathrm{M}$ is a percentage silt plus percentage of very fine sand $(0.002$ to $0.1 \mathrm{~mm})$ multiplied by the quantity (100 minus per cent clay); OM is percentage organic matter; SS is soil structure code: (1) very structured or particulate, (2) fairly structured, (3) slightly structured and (4) solid (Renard et al., 1997; Goldman et al., 1986; Thakur, 2012; Manyiwa and Dikinya, 2013; Panagos et al., 2014; Suraj et al., 2019) and PP is soil profile permeability code: (1) rapid, (2) moderate to rapid, (3) moderate, (4) moderate to slow, (5) slow and (6) very slow. Finally, to convert the result into SI unit, the estimated soil erodibility value was divided by 7.59 .

The databases utilized to determine soil erodibility are (1) soil units (Major soil groups); (2) Soil samples from 56randomly selected locations (with respective coordinates of latitude, longitude and altitude values) in the Shonkola mountainous area, Soro district, in which soil particle size (texture), structure, permeability and organic matter were determined while consideration was given for comparability of topographic setting and land use types.

To determine the values for clay, silt, and fine sand, particle size analysis by measuring the proportion of different sized particles in a soil was employed in the soil laboratory before introducing to the textural class nomograph. The value for organic matter (OM) was estimated for each soil sample using Indian Standard (IS-2720-22, 1972).

$$
O M=\frac{0.67 \times W_{2} \times V}{W_{1} \times W_{3}}
$$

\section{Where}

$\mathrm{W}_{2}$ = weight on oven-dry basis of the soil sample passing $10 \mathrm{~mm}$ sieve

$\mathrm{V}=$ total volume of potassium dichromate used to oxidize the organic matter

$\mathrm{W}_{1}$ = weight on oven-dry basis of the total soil sample before sieving

$\mathrm{W}_{3}$ = weight on oven-dry basis of the soil specimen used in the test

After determination of soil textural classes for each soil sample using nomograph, the values with their geographical referencing coordinates were added to ArcGIS version ArcMAp 10.5. For the study area coverage continuous raster surface was created, through the use of the "Spatial Analyst Tool- interpolation extension (IDWinverse distance weighted method).The raster map is reclassified based on their value range and displayed using cubic convolution (for continuous data) to further enhance the visual attractiveness and create continuous surface.

Soil permeability was determined based on the soil group, soil texture, structure, colour and soil depth. However, the three mainly used properties to determine the soil permeability were soil structure, particle size (soil texture) and soil group. Following the textural classes of soil sample locations, the soil permeability value was determined and coded according to the guidelines adopted by Goldman et al (1986) based on the work of Wischmeier et al (1971) and coded appropriate soil profile permeability (PP) codes from rapid (1) to very slow (6) infiltration rate. 


\section{Results}

The Shonkola mountainous area has two soil types which are pellic vertisols with area coverage of $163.0 \mathrm{~km}^{2}$ and chronic luvisols with area coverage of $22.4 \mathrm{~km}^{2}$. The soil textural classes of the study area are sandy determined as sandy clay, silty clay, clay loam and clayey soil (Figure 2). In the soil erodibility equation, $\boldsymbol{M}$ was estimated based on the percentage values of silt, sand and clay [\% silt (silty clay) plus \%fine sand (sandy clay) multiplied by quantity (100 minus \%clay (clay loam and clayey soil]. The soil erodibility value ranges from $0.0143-0.0202$ metric ton/ha/year in sandy clay soil, 0.0202-0.0240 metric ton/ha/year in clayey, 0.0240-0.0276 metric ton/ha/year in clayey loam to $0.0276-0.0360$ metric ton/ha/year in silty clay soil. The soil erodibility value was reclassified and mapped into four classes that represent the susceptibility of the soil for the detachment and ease of transportation by water erosion (Figure 3). The per cent value for the organic matter was also determined for the sample soils, which ranges from 1.3001 to 3.1985 percent.

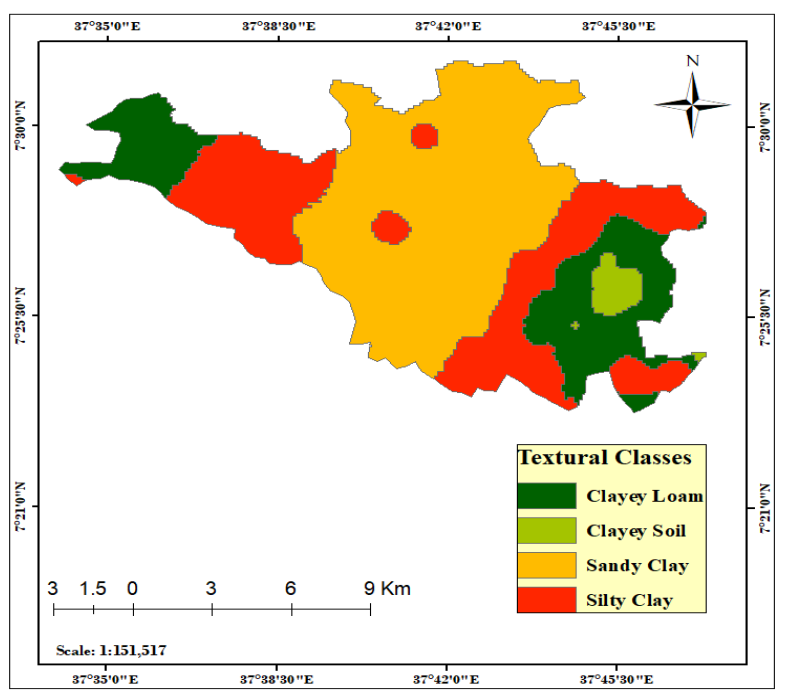

Figure 2: Soil textural classes

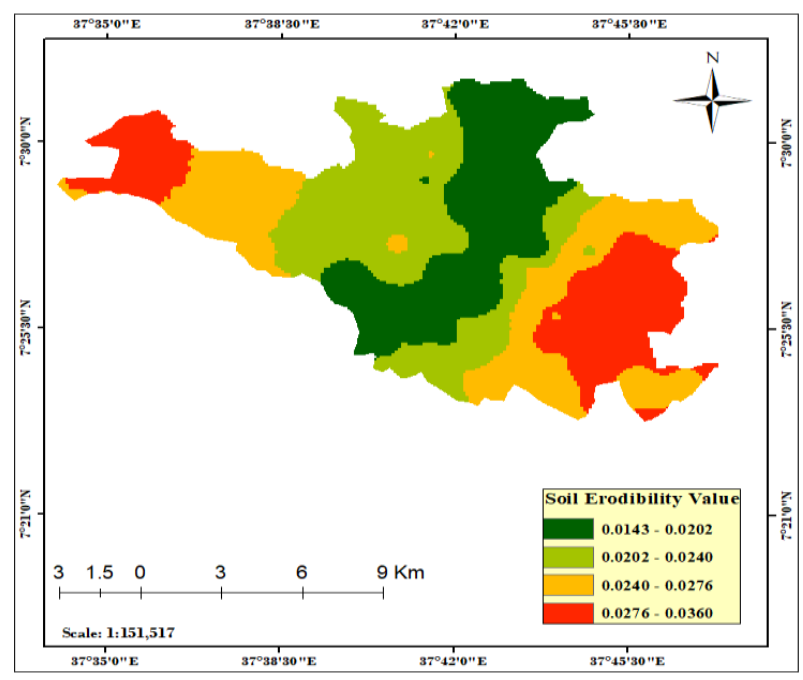

Figure 3: Soil erodibility value

\section{Discussions}

Therefore, the soil that is dominantly silty clay in texture tends to be highly susceptible for water erosion than the soil with high content of sandy clay. The higher the soil erodibility value the more susceptible the soil is and vice versa. Silty soil has higher susceptibility for soil erosion than the clayey soil whereas the soil of high sandy texture tends to have lower erodibility value. The soil erodibility value is minimal in the area where the soil organic matter is higher. This revealed that the organic matter reduces soil erodibility since it reduces the susceptibility of the soil to the detachment, and as well increases the rate of percolation, which in turn, lessen runoff and therefore soil erosion.

It was found that the soil erodibility (or its vulnerability to erosion) generally increases as organic content decreases, soil texture becomes finer and less permeable, and structure becomes poor. However, the overall result of this study in Shonkola mountainous area of Soro district showed that erodibility status is generally high. This implies that the extensive erosion in the Shonkola mountainous area is as a result of the soil erodibility status rather than some other factors of erosion such as rainfall intensity and duration, land use practice, land cover and management practice. The extent of soil erodibility is a function of its physico-chemical makeups, especially, textural and structural 
classes, organic materials, and soil permeability or capacity of water infiltration (Manyiwa and Dikinya, 2013).

As of the soil units, the study area has two dominant soil groups: pellic vertisols and chronic luvisols. Pellic vertisols are characterized by a clay-size-particle content of 30 percent or more by mass in all horizons (layers) of the upper halfmetre of the soil profile, by cracks at least $1 \mathrm{~cm}$ (0.4 inch) wide extending downward from the land surface, and by evidence of strong vertical mixing of the soil particles over many periods of wetting and drying. They are found typically on level or mildly sloping topography in climatic zones that have distinct wet and dry seasons and found to be minimal to moderately erodible. Whereas the area with chronic luvisols are more likely susceptible for soil erosion since these soils have high erodibility value.

\section{References}

\section{Barrow C (1991) Land Degradation:} Development and Breakdown of Terrestrial Environments, Pp. 295. Cambridge, UK: Cambridge University Press, Pp. 295.

Berhanu D (1985) The Vertisols of Ethiopia, their characteristics, classification and management. In: Fifth Meeting of the Eastern African Sub-Committee for Soil Correlation and Land Evaluation, Wad Medani, Sudan, 5-10 December 1983. World Soil Resources Report No. 56. FAO (Food and Agriculture Organization), Rome. Pp. 31-54.

FAO/UNESCO (1981). (United Nations Food and Agriculture Organization, and Educational, Scientific and Cultural Organization). (1981). FAO-UNESCO soil map of the world, 1: 5,000,000. Paris: UNESCO.

Hussein B, Alaa M and Wasan S (2016) Estimation Of Soil Erosion In Northern Kirkuk Governorate, Iraq Using RUSLE, Remote Sensing AND GIS; Carpathian $J$. Earth, Evn. (11)1:153 - 166.

Goldman S., Jackson K. and Bursztynsky T. (1986). Erosion and Sediment Control
Handbook. New York: McGraw-Hill. p. 340.

IS 2720-22 (1972) Methods of test for soils, Part 22: Determination of organic matter [CED 43: Soil and Foundation Engineering Pp.5-12

International Food Policy Research Institute (IFPRI) (2012) 2011 Global food policy report. Washington, D.C. p.520

Lal R (2015) Restoring soil quality to mitigate soil degradation; Sustain. .7: 5875-5895

Manyiwa T and Dikinya O (2013) Using universal soil loss equation and soil erodibility factor to assess soil erosion in Tshesebe village, north east Botswana; Afr. J. Agr. Res. 8(30): 41704178.

Menale K and Holden S (2006) Parametric and Non-parametric Estimation of Soil Conservation Impact on Productivity in the Northwestern Ethiopian Highlands: Contributed paper prepared for presentation at the international Association of Agricultural Economists Conference, Gold Coast, Australia: Pp. 1-15

Tsitsagi M, Berdzenishvili A and Gugeshashvili M (2018) Spatial and temporal variations of rainfall-runofferosivity (R) factor in Kakheti, Georgia; Ann. Agra. Sci.16: 226-235.

Panagos P, Meusburger K, Ballabio C, Borrelli P, and Alewell C (2014) Soil erodibility in Europe: A high-resolution dataset based on LUCAS; Science of The Total Environment, 479-480:189-200.

Renard K, Foster G, Weesies G, McDool D, and Yoder D (1997) Predicting Soil Erosion by Water: A Guide to Conservation Planning with the Revised Universal Soil Loss Equation (RUSLE), USDA, Agricultural Handbook, Washington, DC, 703: Pp. 384.

Shimeles D (2012) Effectiveness of Soil and Water Conservation Measures for Land Restoration in Wello Area, Northern Ethiopian Highlands, Ecol. Develo. Series, 89: 5-19.

Suraj B, Kumaraperumal R Balaji K, Ragunath K. and Backiyavathy M. (2019) Soil erodibility estimation and its correlation with soil 
properties in Coimbatore district; Int. J. Chem. Stud. 7(3): 3327-3332.

Thakur, B (2012) Soil Erosion Assessment in Solani Watershed Using Geospatial Tools, $A$ J. Assoc. Punjab Geog. , India, 8: 39-59.

Vlek, P, Le Q, and Tamene L (2010) Assessment of Land Degradation, Its Possible Causes and Threat to Food Security in Sub-Saharan Africa. In: Rattan and Stewart (Ed), Advances in Soil Science: Food Security and Soil Quality, Pp. 57-86.

Wischmeier W and Smith D (1978) Predicting Rainfall Erosion Losses: $A$ guide to conservation planning, U.S. Dep. Agric., Agric. Handb. No. 537.

Wischmeier W, Johnson C and Cross B (1971) A Soil erodibility nomograph for farmland and construction sites. J. Soi Water Conser. 26: 189-193.

$* * * * * * * * *$ 